\title{
More than identifiers: Map symbols and their connotative meaning
}

\author{
Silvia Klettner \\ TU Wien, Department of Geodesy and Geoinformation, Research Division Cartography, silvia.klettner@tuwien.ac.at
}

Keywords: visual communication, cartography, map symbols, semiotics

\begin{abstract}
:
Cartographic maps are a form of communication. Through signs and symbols, they give rise to ideas and thoughts of geospatial phenomena, enabling us to relate to, think about, and to imagine events from a viewpoint beyond direct experience. By applying a mutually shared set of signs and semiotic rules, sheer unlimited, meaningful, novel messages about space and time can be communicated through maps. As such, maps are considered a means of conceiving, articulating, and structuring the human world (Harley, 1989).
\end{abstract}

Maps are human-made artifacts, based on a myriad of choices concerning what to communicate and how to communicate. Maps are, therefore, never neutral but based on decisions which will influence how maps are perceived, how information is interpreted, and how phenomena and events are imagined (Chandler, 2007; Monmonier, 1996). Cartographic communication, therefore, requires deliberate choices to share and express information successfully. To this day, the cartographer faces the challenge of near-infinite variations of visual variables to choose from. Yet, which ones are most suitable for a given context, for a given type of spatial information, object, or phenomenon? The choice for the aptest cartographic signifier is still a challenging task. In cartography, there remains a need for a differentiated understanding of how visual variables can be used to encode information (MacEachren et al., 2012).

While all map signs can be considered to be identifiers which aim to denote and inform about spatial phenomena, research from related fields show that signs and symbols may also imbue connotative qualities that influence human affect and modulate cognitive processes (e.g. Feldman Barrett et al., 2007; Loftus \& Palmer, 1974). In as far as cartographic semiology provides a theoretical framework addressing the denoting qualities of cartographic visual variables (Bertin, 1974), it, hitherto, does not encompass their connotative effects on human affect, perception, and cognition. At the same time, empirical research on the connotative meaning of map signs is still scarce, and semiotic differentiations between the denoting and connoting qualities of signifiers are often neglected in cartographic research and applications of semiotics. Consequently, "the difference of what a map sign means and what it represents has become blurred" (MacEachren, 1995, p.245).

Between the intersection of psychology, cartography, and semiotics, this research draws attention to the connotative qualities of shape symbols in cartographic communication. In qualitative and quantitative empirical studies, abstract map symbols are studied in cartographic and non-cartographic contexts, and their connotative effects on human judgments and affective responses are explored (Klettner, 2019, 2020). Shape symbols, in these studies, refer to commonly used graphic variables in visual communication and thematic cartography (e.g. circle, triangle, square, etc.) to indicate nominal data. Findings strongly indicate that some map symbols do not only depict and denote but also express and connote and that these connotative qualities can be as powerful as to modulate affective responses and cognitive processes, such as influencing judgments about the depicted phenomena.

A better understanding of how map signs and symbols are perceived can allow for more accurate discrimination between them. By unraveling some of the connotative qualities of cartographic point symbols, this research aims to contribute towards more informed choices and towards creating more effective and associative cartographic visualizations.

\section{References}

Bertin, J. (1974). Graphische Semiologie: Diagramme, Netze, Karten. Walter de Gruyter.

Chandler, D. (2007). Semiotics: The Basics. Routledge.

Feldman Barrett, L., Mesquita, B., Ochsner, K. N., \& Gross, J. J. (2007). The Experience of Emotion. Annu. Rev. Psychol., 58, 373-403. 
Harley, J. B. (1989). Deconstructing the map. Cartographica, 26(2), 1-20.

Klettner, S. (2019). Why Shape Matters-On the Inherent Qualities of Geometric Shapes for Cartographic Representations. ISPRS International Journal of Geo-Information, 8(5), 217.

Klettner, S. (2020). Affective Communication of Map Symbols: A Semantic Differential Analysis. ISPRS International Journal of Geo-Information, 9(5), 289.

Loftus, E. F., \& Palmer, J. C. (1974). Reconstruction of Automobile Deconstruction: An Example of the Interaction Between Language and Memory. Journal of Verbal Learning and Verbal Behavior, 13(5).

MacEachren, A. M., Roth, R. E., O’Brien, J., Li, B., Swingley, D., \& Gahegan, M. (2012). Visual Semiotics and Uncertainty Visualization: An Empirical Study. IEEE Transactions on Visualization and Computer Graphics, 18(12), 2496-2505.

MacEachren, Alan M. (1995). How Maps Work: Representation, Visualization, and Design. The Guilford Press.

Monmonier, M. (1996). How to Lie with Maps. The University of Chicago Press. 